\title{
The Effect of Alumina and Magnesia Supported Germanium Nanoparticles on the Growth of Carbon Nanotubes in the Chemical Vapor Deposition Method
}

\author{
Ghazaleh Allaedini, ${ }^{1}$ Payam Aminayi, ${ }^{2}$ and Siti Masrinda Tasirin ${ }^{1}$ \\ ${ }^{1}$ Department of Chemical and Process Engineering, Universiti Kebangsaan Malaysia, 43600 Bangi, Selangor, Malaysia \\ ${ }^{2}$ Department of Chemical and Paper Engineering, College of Engineering and Applied Sciences, Parkview Campus, \\ Kalamazoo, MI 49008, USA
}

Correspondence should be addressed to Ghazaleh Allaedini; jiny_ghazaleh@yahoo.com

Received 18 February 2015; Revised 14 April 2015; Accepted 21 April 2015

Academic Editor: Xiao-Ping Dong

Copyright (C) 2015 Ghazaleh Allaedini et al. This is an open access article distributed under the Creative Commons Attribution License, which permits unrestricted use, distribution, and reproduction in any medium, provided the original work is properly cited.

\begin{abstract}
The effect of alumina and magnesia supported germanium (Ge) nanoparticles on the synthesis of carbon nanotubes (CNTs) using the chemical vapor deposition (CVD) method in atmospheric pressure was investigated. The TEM micrographs confirmed the formation of carbon nanotubes, and the field emission scanning electron microscopy (FESEM) analysis suggested a tip-growth mechanism for the grown carbon nanotubes. The X-ray diffraction (XRD) pattern indicated a graphitic nature of the carbon nanotubes. The obtained CNTs using Ge nanoparticles supported by $\mathrm{MgO}$ resulted in a higher degree of graphitization than the CNTs obtained using Ge nanoparticles supported by $\mathrm{Al}_{2} \mathrm{O}_{3}$. Raman spectroscopy analysis of the CNTs confirmed the presence of radial breathing modes (RBM), which verified the formation of CNTs. High frequency Raman analysis demonstrated that the degree of graphitization of the synthesized CNTs using magnesia supported Ge nanoparticles is higher than that of the alumina supported Ge nanoparticles with the values of $\left(I_{\mathrm{D}} / I_{\mathrm{G}}\right)$ ratios equal to 0.45 and 0.73 , respectively.
\end{abstract}

\section{Introduction}

Carbon nanotubes (CNTs) have attracted attention in the last decade because of their mechanical, electrical, thermal, and chemical properties. Prominent properties of CNTs, including their strength and elasticity reported with Young's module value of up to $2 \mathrm{TPa}$ [1], the high aspect ratios of CNTs (1000:1), and their exceptional electrical conductivity at much lower loading when compared with stainless steel, have attracted a great deal of interest [2]. CNTs' superior field emission properties, because of their emission at low voltages, make them preferred over conventional electron sources [3]. Moreover, CNTs have been used for hydrogen storage [4].

Numerous methods have been employed to synthesize CNTs, including plasma based arc discharge and laser ablation in addition to the thermal methods, such as chemical vapor deposition (CVD), plasma enhanced chemical vapor deposition (PECVD), alcohol catalytic CVD (ACCVD), hydrothermal or sonochemical process, and high-pressure CO conversion (HiPCo) [5]. Nevertheless, the CVD method has significant advantages over the other methods. The CVD method is widely used for carbon nanotube synthesis because of its high production yield and scale-up capability [6].

In the CVD method, a catalyst is usually used to help growing carbon nanotubes. These catalysts are mostly transition metals such as $\mathrm{Ni}, \mathrm{Fe}$, and $\mathrm{Co}$ [7]. In addition to transition metals, semiconductor nanoparticles such as $\mathrm{SiC}$, $\mathrm{Si}$, and Ge have also been shown to be effective in the synthesis of carbon nanotubes because of their capability to dissolve carbon effectively for the CNT growth [8]. The catalytic decomposition of the carbon precursor molecules on the surface of the metal catalyst particles is followed by the diffusion of the released carbon atoms into the metal particles. Carbon saturation in the metal occurs either by reaching the carbon solubility limit in the metal at a given temperature or by lowering the solubility limit via 
a temperature decrease. Super saturation results in the solid carbon precipitation over the metal particles. However, the success of semiconductors in the CNT production suggests that only nanoscale curvatures would be enough to obtain CNTs in the presence of a carbon source. Therefore, in this study, Ge nanoparticles were used to produce CNTs.

The physical shape of the precipitated carbon depends on several parameters including the catalyst/semiconductor nanoparticle and its size [9], the use of support [10], and the precipitation rate [11]. The use of support is one of the key factors in the catalyst/nanoparticle preparation for the CVD process. In the synthesis of CNTs, the same catalyst can act differently in the presence of different supports. The commonly used supports in the CVD process are quartz, silica, alumina, zeolite, $\mathrm{CaCO}_{3}$, and magnesia [12]. The support material and its morphology and textural properties greatly affect the yield and quality of the resulting CNTs. Accordingly, the effect of magnesia and alumina supports in the presence of Ge nanoparticles in a CVD process on the obtained CNTs has been investigated in this paper.

\section{Materials and Methods}

For the catalyst synthesis, oleic acid, oleyamine, and methanol were stirred in a $20 \mathrm{~mL}$ beaker and mixed well for 4 hours. Then, $0.6 \mathrm{mmol}$ of germanium iodide $\left(\mathrm{GeI}_{2}\right)$ and $0.4 \mathrm{mmol}$ of magnesia with molar ratio of $0.6: 0.4$ were added to the mixture. The reaction temperature was gradually increased from $80^{\circ} \mathrm{C}$ to $160^{\circ} \mathrm{C}$ in 4 hours (20 degrees every 1 hour) [13]. It was observed that the yellowish color of the solution changed to a brownish color, indicating that the reaction had taken place. The resulting solution was sealed and transferred to an oven and dried at $100^{\circ} \mathrm{C}$. The obtained powder was then washed 3 times with distilled water, centrifuged at $7000 \mathrm{rpm}$, and calcined at $500^{\circ} \mathrm{C}$ for 4 hours. In a separate run of the experiment, the same methodology was conducted with the exception of using alumina instead of magnesia in order to investigate the effect of the support.

For the CNT production, $2 \mathrm{~g}$ of the obtained catalysts were placed in the CVD reactor and heated in the presence of $\mathrm{N}_{2}$ to $600^{\circ} \mathrm{C}$. The reactor was then purged with $\mathrm{H}_{2}$ while the temperature was maintained at $600^{\circ} \mathrm{C}$ for 1 hour. After that, the temperature of the reactor was increased to $1000^{\circ} \mathrm{C}$ in the presence of $\mathrm{N}_{2}$. Once the temperature was stabilized at $1000^{\circ} \mathrm{C}$, the methane gas was introduced to the reaction tube with a flow rate of $500 \mathrm{~mL} / \mathrm{min}$ for 3 hours. The reactor was then cooled down to the ambient temperature while passing $\mathrm{N}_{2}$ gas for 30 minutes. The obtained powder was collected and purified using $50 \mathrm{~mL}$ of concentrated $\mathrm{HCl}$ for further characterization. Field emission scanning electron microscopy (FESEM) pictures were obtained to visualize the surface morphology of the produced CNTs, using a Zeiss SUPRA55 scanning electron microscope at an operating voltage of $3 \mathrm{kV}$. Transmission electron microscopy (TEM) was performed to visualize the nanotubes (Hitachi477700m10 Kv). Energydispersive X-ray spectroscopy (EDX) (Zeiss SUPRA55) was used to investigate the weight percentages of the present elements in the synthesized powder. Raman spectrophotometer,
TABLE 1: Weight percentages of different components present in the obtained $\mathrm{Ge}-\mathrm{MgO}-\mathrm{CNT}$ and $\mathrm{Ge}-\mathrm{Al}_{2} \mathrm{O}_{3}$-CNT.

\begin{tabular}{lcccc}
\hline \multirow{2}{*}{ Element } & \multicolumn{2}{c}{$\mathrm{Ge}-\mathrm{MgO}-\mathrm{CNT}$} & \multicolumn{2}{c}{${\mathrm{Ge}-\mathrm{Al}_{2} \mathrm{O}_{3} \text {-cnt }}$} \\
& Weight \% & Atomic \% & Weight \% & Atomic \% \\
\hline $\mathrm{C}$ & 74.01 & 80.26 & 54.57 & 64.78 \\
$\mathrm{O}$ & 16.88 & 14.50 & 24.90 & 22.99 \\
$\mathrm{Mg}$ & 5.11 & 2.74 & - & - \\
$\mathrm{Al}$ & - & - & 17.28 & 10.13 \\
$\mathrm{Ge}$ & 4 & 2.50 & 3.25 & 2.10 \\
Total & 100.00 & & 100.00 & \\
\hline
\end{tabular}

with a laser source operating at the wavelength of $514 \mathrm{~nm}$ (Horiba Jobin Yvon, LabRam HR800), was used to confirm the formation of CNTs.

\section{Result and Discussion}

FESEM was employed for the analysis of the morphology and density of the obtained CNTs. The FESEM pictures of the catalysts before the experiment are shown in Figures 1(a) and 1 (b) for the $\mathrm{Ge} / \mathrm{MgO}$ and $\mathrm{Ge} / \mathrm{Al}_{2} \mathrm{O}_{3}$ supported catalysts, respectively. These pictures show the flower-like morphology and high surface area of the catalysts. The SEM images, which show the CNT growth in the presence of $\mathrm{Ge} / \mathrm{MgO}$ and $\mathrm{Ge} / \mathrm{Al}_{2} \mathrm{O}_{3}$ catalysts, are presented in Figures $1(\mathrm{c}), 1(\mathrm{~d}), 1(\mathrm{e})$, and $1(\mathrm{f})$. The high aspect ratio nanostructures of the CNTs are observed in these pictures. The nanotubes were grown on the surface of the Ge nanoparticles. This suggests that the tip-growth mechanism is likely to be the possible mechanism for the CNT synthesis under the present conditions [14]. The area density of the deposited CNTs appeared to be high, and the CNTs structures had randomly oriented spaghetti-like morphology in both cases after the purification (see Figures $1(\mathrm{~g})$ and $1(\mathrm{~h})$ ).

The TEM micrographs of the obtained CNTs after purification confirmed the formation of the nanotubes. The diameter and the morphology of the obtained CNTs can also be investigated using the TEM pictures (Figure 2). The carbon nanotubes are distinguished in Figure 2 by their hollow compartments with average diameters of $16.1 \mathrm{~nm}$ and $21.4 \mathrm{~nm}$ for $\mathrm{Ge} / \mathrm{MgO}-\mathrm{CNT}$ and $\mathrm{Ge} / \mathrm{Al}_{2} \mathrm{O}_{3}-\mathrm{CNT}$, respectively.

The EDX spectrum obtained from GeMgO-CNT and $\mathrm{GeAl}_{2} \mathrm{O}_{3}$-CNT samples are shown in Figures 3(a) and 3(b). As can be observed in Table 1, the weight percentage of carbon in the obtained CNTs when $\mathrm{MgO}$ supported $\mathrm{Ge}$ is used is higher (74.01\%) than that of the $\mathrm{Al}_{2} \mathrm{O}_{3}$ supported $\mathrm{Ge}$ (54.57\%).

XRD analysis was carried out to examine the crystalline structure of the CNTs, and the spectra of Ge/MgO-CNT and $\mathrm{Ge} / \mathrm{Al}_{2} \mathrm{O}_{3}-\mathrm{CNT}$ are presented in Figures 4(a) and 4(b), respectively. The peak at $2 \theta=26^{\circ}$ is attributed to the graphitic peak confirming the presence of carbon nanotubes in the sample. For $\mathrm{Ge} / \mathrm{MgO}-\mathrm{CNT}$, the peak at $2 \theta=44^{\circ}$ is attributed to the (101) plane of the nanotube, and the peak at $2 \theta=$ $43^{\circ}$ is assigned to the CNTs obtained from $\mathrm{Ge} / \mathrm{Al}_{2} \mathrm{O}_{3}$. The intensity of the main CNT peak (002) is lower when Ge 


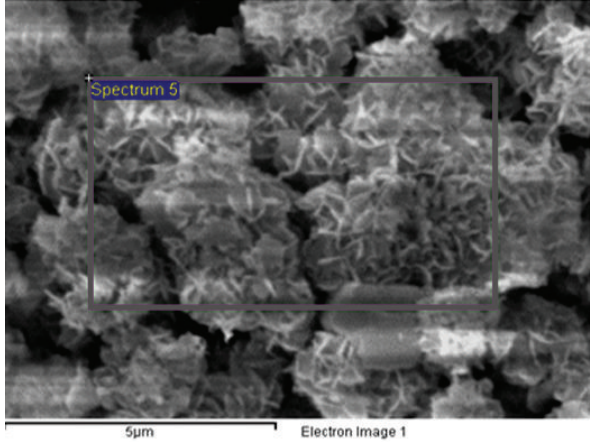

(a)

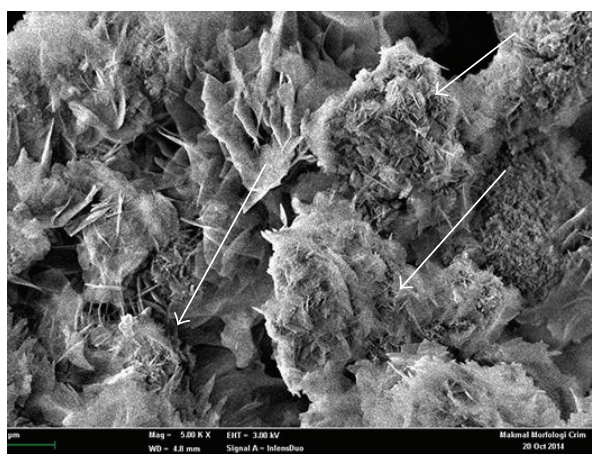

(c)

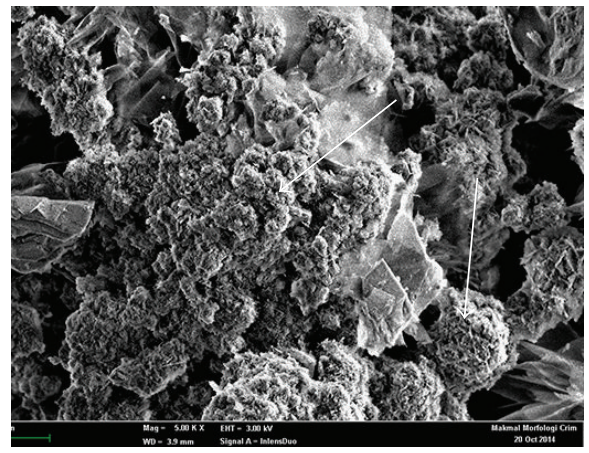

(e)

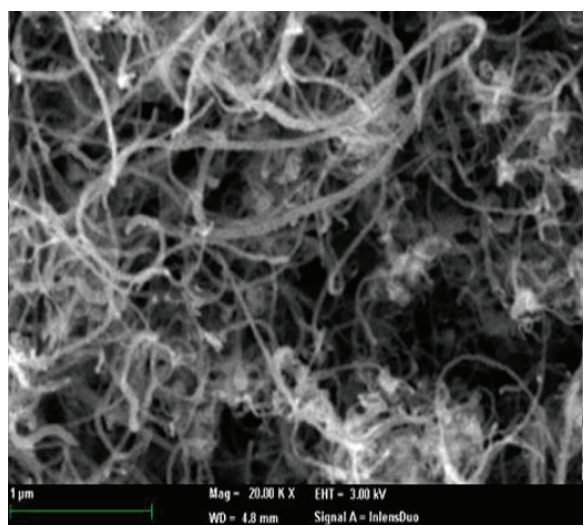

(g)

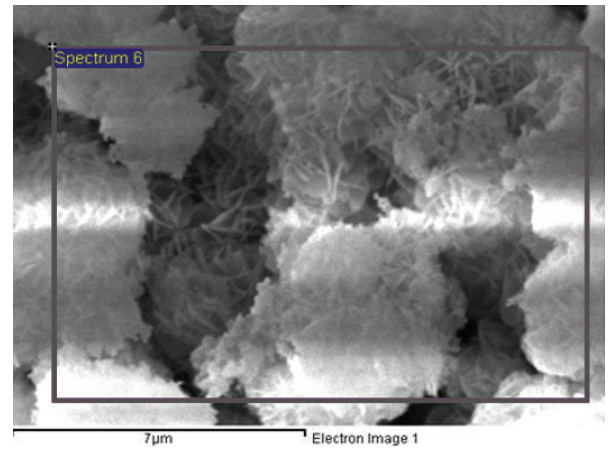

(b)

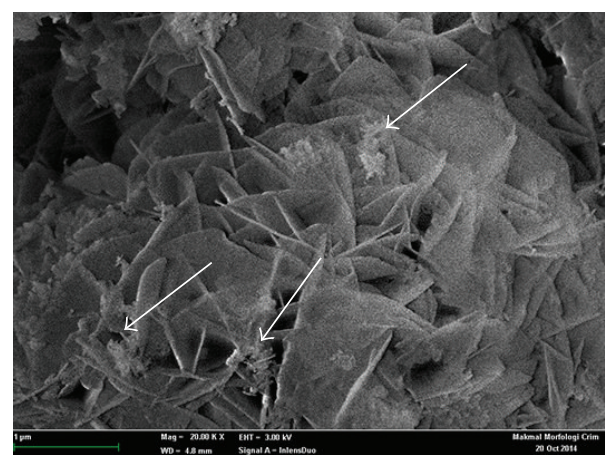

(d)

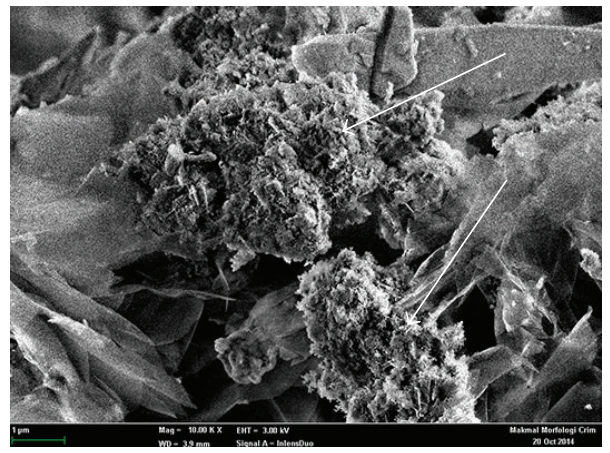

(f)

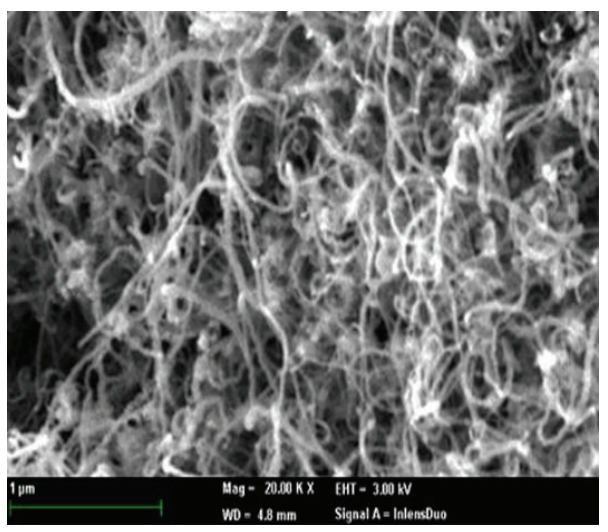

(h)

Figure 1: SEM images of (a) Ge/MgO, (b) $\mathrm{Ge} / \mathrm{Al}_{2} \mathrm{O}_{3},\left((\mathrm{c})\right.$, (d)) Ge/MgO-CNT, ((e), (f)) $\mathrm{Ge} / \mathrm{Al}_{2} \mathrm{O}_{3}$-CNT, (g) CNTs obtained from Ge/MgO, and (h) CNTs obtained from $\mathrm{Ge} / \mathrm{Al}_{2} \mathrm{O}_{3}$. 


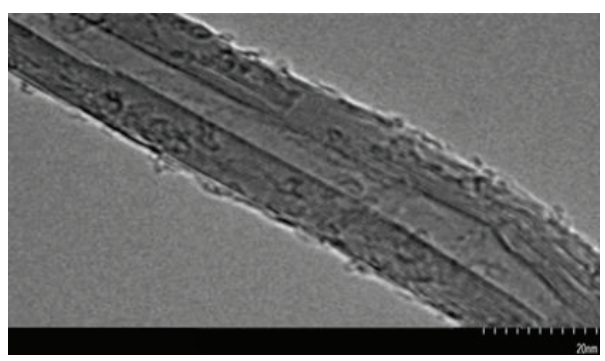

(a)

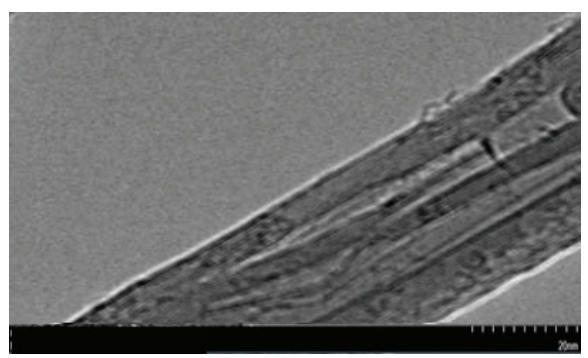

(b)

Figure 2: TEM images of CNTs obtained using (a) Ge/MgO and (b) $\mathrm{Ge} / \mathrm{Al}_{2} \mathrm{O}_{3}$.

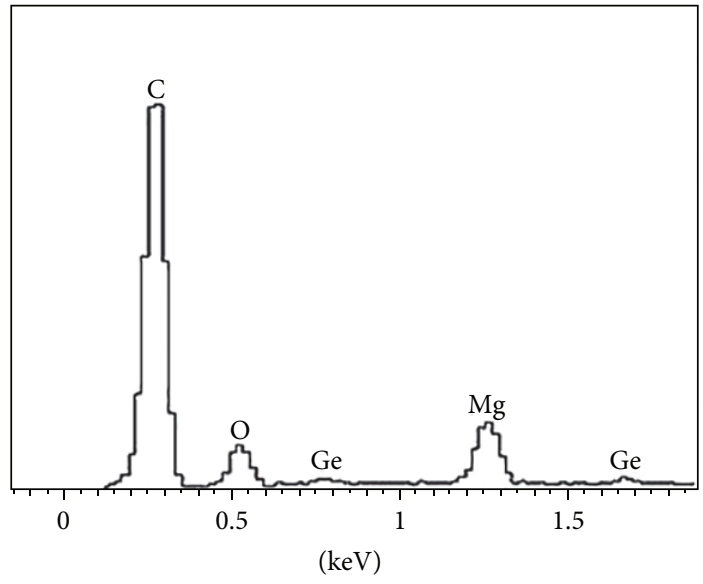

Full scale 3373 cts cursor: -0.156 ( 0 cts)

(a)

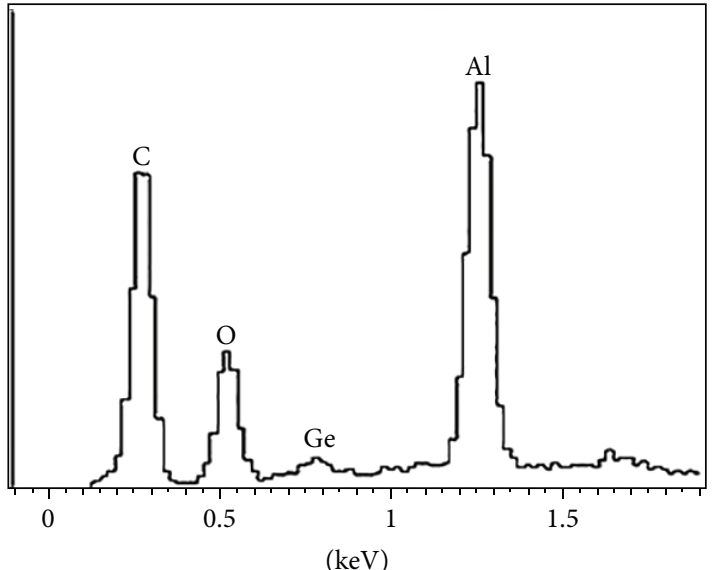

Full scale 1373 cts cursor: -0.109 (0 cts)

(b)

Figure 3: EDX spectrum of (a) Ge/MgO-CNT and (b) $\mathrm{Ge} / \mathrm{Al}_{2} \mathrm{O}_{3}-\mathrm{CNT}$.

is supported by $\mathrm{Al}_{2} \mathrm{O}_{3}$, which may be the reason for the absence of the (101) peak and, instead, the presence of (100) in its diffraction pattern [15]. The broader full width at half maximum (FWHM) of the (002) peak of Ge/MgO-CNT indicates a lower crystallinity in comparison with $\mathrm{Ge} / \mathrm{Al}_{2} \mathrm{O}_{3}$ $\mathrm{CNT}$. The peaks attributed to the presence of $\mathrm{MgO}, \mathrm{Al}_{2} \mathrm{O}_{3}$, and Ge are shown in Figures 4(a) and 4(b).

Raman spectroscopy determines the details of the quality and structure of the produced carbon nanotubes. Figure 5 shows the Raman spectra of the carbon nanotubes at room temperature. The presented spectra are divided into two main zones: the low frequency in the $150-400 \mathrm{~cm}^{-1}$ region (shown as an insert in Figure 4) and the high frequency zone of 0 $3000 \mathrm{~cm}^{-1}$.

Evidence for the presence of Radial Breathing Mode $(\mathrm{RBM})$ vibrations in $\mathrm{Ge} / \mathrm{MgO}-\mathrm{CNT}$ and $\mathrm{Ge} / \mathrm{Al}_{2} \mathrm{O}_{3}-\mathrm{CNT}$ samples is obtained from the low wave number range of the spectra (insert of Figure 4). The presence of RBM is indicative of the presence of CNTs. Since RBM is not present in the graphite, this range of frequency can be investigated to confirm the CNTs formation. In the RBM, all of the carbon atoms move in the radial direction and generate a breathing-like vibration [16]. The peaks located at $180 \mathrm{~cm}^{-1}$ and $270 \mathrm{~cm}^{-1}$ in the Raman spectra of Ge/MgO-CNT are due to the RBM of CNTs. The RBM vibrations for $\mathrm{Ge} / \mathrm{Al}_{2} \mathrm{O}_{3}-\mathrm{CNT}$ are located at $190 \mathrm{~cm}^{-1}$ and $290 \mathrm{~cm}^{-1}$ [16]. The observation of the RBM in the Raman spectra of the prepared CNTs samples is indicative of the high purity of the samples, specifically for $\mathrm{Ge} / \mathrm{MgO}-\mathrm{CNT}$ with lower RBM $\left(180,270 \mathrm{~cm}^{-1}\right)$ than $\mathrm{Ge} / \mathrm{Al}_{2} \mathrm{O}_{3}$-CNT (190 and $290 \mathrm{~cm}^{-1}$ ) [17].

Two main peaks observed in the high frequency zone of the obtained Raman spectra are the D and G bands. The G-band is attributed to the stretching mode of the $\mathrm{C}-\mathrm{C}$ bond in the graphite plane and demonstrates the presence of crystalline graphitic carbon. For both $\mathrm{Ge} / \mathrm{MgO}-$ $\mathrm{CNT}$ and $\mathrm{Ge} / \mathrm{Al}_{2} \mathrm{O}_{3}-\mathrm{CNT}$, the $\mathrm{G}$ band appears at $1560 \mathrm{~cm}^{-1}$. The D-band, centered around $1350 \mathrm{~cm}^{-1}$, originates from the disorder in the $\mathrm{sp}^{2}$-hybridised carbon and is an indication of the presence of lattice defects in the graphite sheet that make up the CNT layers. The $I_{\mathrm{D}} / I_{\mathrm{G}}$ intensity ratio is reported to increase with an increase in the structural disorder of the CNTs. Lower $I_{\mathrm{D}} / I_{\mathrm{G}}$ values are representative of wellgraphitized CNTs. The values of $\left(I_{\mathrm{D}} / I_{\mathrm{G}}\right)$ for the CNTs grown using $\mathrm{Ge} / \mathrm{MgO}$ and $\mathrm{Ge} / \mathrm{Al}_{2} \mathrm{O}_{3}$ nanoparticles are calculated to be 0.45 and 0.73 , respectively. The $I_{\mathrm{D}} / I_{\mathrm{G}}$ values confirm that the degree of long-range ordered crystalline perfection of CNTs grown using $\mathrm{MgO}$ as support is higher than that of the CNTs grown using $\mathrm{Al}_{2} \mathrm{O}_{3}$ as support. These results 


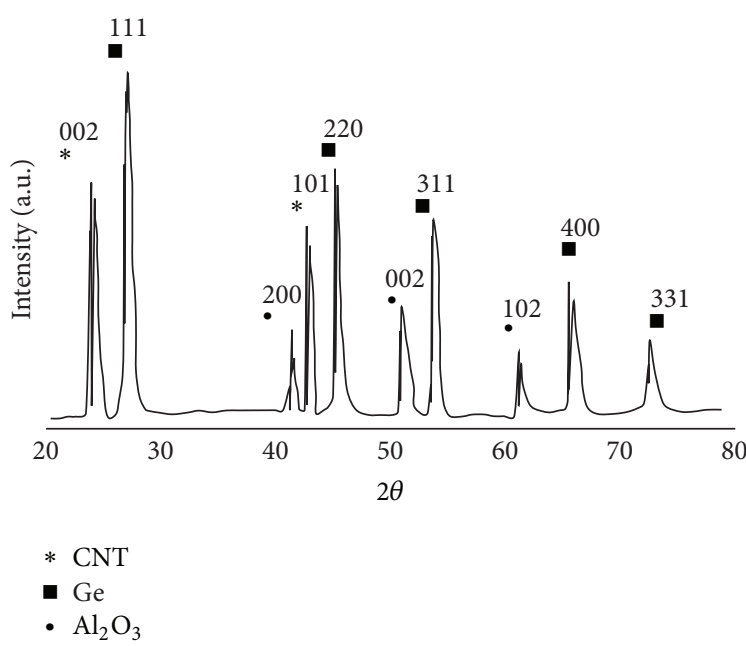

(a)

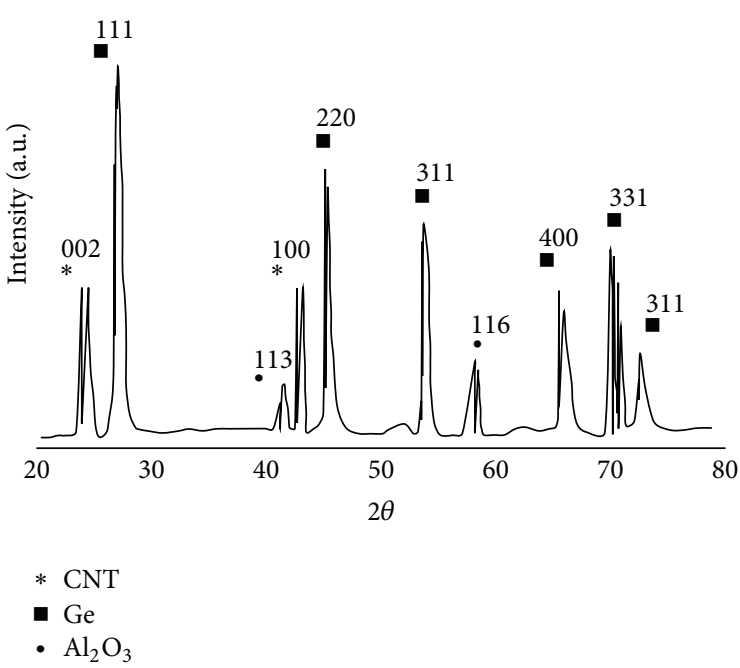

(b)

Figure 4: XRD spectra of (a) Ge/MgO-CNT and (b) $\mathrm{Ge}_{\mathrm{Al}} \mathrm{Al}_{2} \mathrm{O}_{3}-\mathrm{CNT}$. Ge/MgO-CNT exhibits a lower crystallinity in comparison with $\mathrm{Ge} / \mathrm{Al}_{2} \mathrm{O}_{3}-\mathrm{CNT}$.

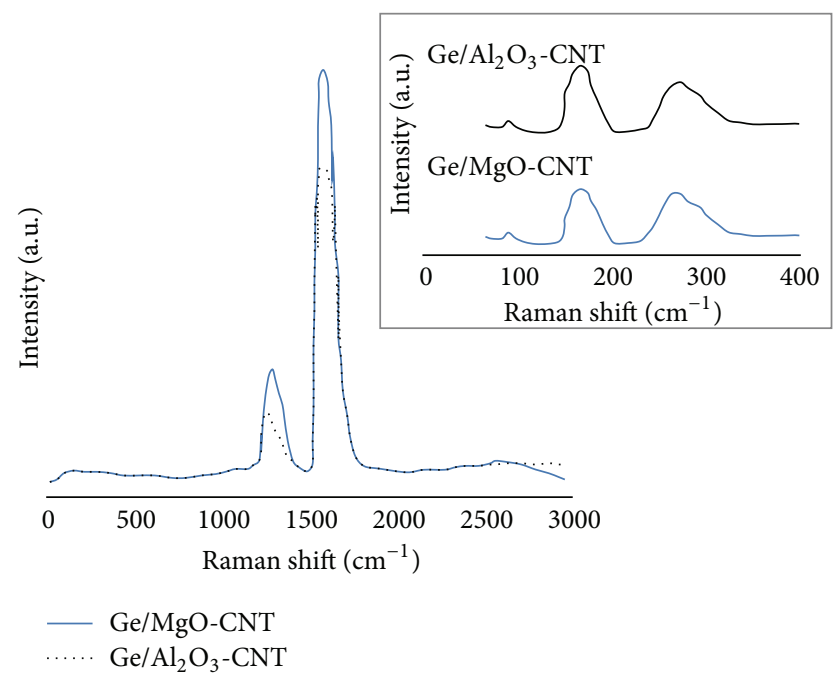

FIGURE 5: High frequency Raman spectrum of Ge/MgO-CNT and $\mathrm{Ge} / \mathrm{Al}_{2} \mathrm{O}_{3}$-CNT, (insert) Low frequency Raman spectrum of $\mathrm{Ge} / \mathrm{MgO}-\mathrm{CNTs}$ and $\mathrm{Ge} / \mathrm{Al}_{2} \mathrm{O}_{3}$-CNTs.

are consistent with the XRD results. Therefore, it can be concluded that the degree of graphitization of the CNTs is affected by using different supports for the catalysts.

\section{Conclusion}

Carbon nanotubes have been synthesized successfully by the decomposition of methane in the CVD process, and the effect of two different supports for the Ge nanoparticles on the CNT growth has been investigated. This study reveals that the use of different supports strongly affects not only the crystallinity but also the yield, morphology, and microstructure of the catalyst. The XRD and Raman spectroscopy of the CNTs grown over the Ge nanoparticles supported by $\mathrm{MgO}$ resulted in a higher degree of graphitization when compared to that of the $\mathrm{Ge}$ nanoparticles supported by $\mathrm{Al}_{2} \mathrm{O}_{3}$. The Raman spectra of $\mathrm{Ge} / \mathrm{MgO}-\mathrm{CNT}$ and $\mathrm{Ge} / \mathrm{Al}_{2} \mathrm{O}_{3}-\mathrm{CNT}$ were used to calculate the values of the $\left(I_{\mathrm{D}} / I_{\mathrm{G}}\right)$ ratios equal to 0.45 and 0.73 , respectively. The tip-growth mechanism, which signals the use of supports, was observed in the SEM results. The TEM micrographs confirmed the formation of carbon nanotubes with small average diameters equal to $16.1 \mathrm{~nm}$ and $21.4 \mathrm{~nm}$ for $\mathrm{Ge} / \mathrm{MgO}-\mathrm{CNTs}$ and $\mathrm{Ge} / \mathrm{Al}_{2} \mathrm{O}_{3}-\mathrm{CNTs}$, respectively. Evidence of the presence of RBM in the spaghetti-like metal-filled tubes was obtained from the low frequency Raman spectrum analysis. It was concluded that $\mathrm{MgO}$ supported $\mathrm{Ge}$ will result in CNTs with superior properties than the $\mathrm{Al}_{2} \mathrm{O}_{3}$ supported Ge.

\section{Conflict of Interests}

The authors declare no conflict of interests.

\section{Acknowledgments}

The authors would like to acknowledge the support provided by the CRIM, DIP-2012-05, and FRGS/2/2013/TK05/ UKM/02/3 funds, UKM, Malaysia.

\section{References}

[1] R. B. Pipes and P. Hubert, "Helical carbon nanotube arrays: mechanical properties," Composites Science and Technology, vol. 62, no. 3, pp. 419-428, 2002.

[2] J. Li, Q. Zhang, and M. B. Chan-Park, "Simulation of carbon nanotube based $\mathrm{p}-\mathrm{n}$ junction diodes," Carbon, vol. 44, no. 14, pp. 3087-3090, 2006.

[3] J.-M. Bonard, N. Weiss, H. Kind et al., "Tuning the field emission properties of patterned carbon nanotube films," Advanced Materials, vol. 13, no. 3, pp. 184-188, 2001. 
[4] A. Chambers, C. Park, R. T. K. Baker, and N. M. Rodriguez, "Hydrogen storage in graphite nanofibers," The Journal of Physical Chemistry B, vol. 102, no. 22, pp. 4253-4256, 1998.

[5] K. Varshney, "Carbon nanotubes: a review on synthesis, properties and applications," International Journal of Engineering Research, vol. 2, no. 4, pp. 660-677, 2014.

[6] Y.-M. Shyu and F. C.-N. Hong, "Low-temperature growth and field emission of aligned carbon nanotubes by chemical vapor deposition," Materials Chemistry and Physics, vol. 72, no. 2, pp. 223-227, 2001.

[7] F. Ding, P. Larsson, J. A. Larsson et al., "The importance of strong carbon-metal adhesion for catalytic nucleation of singlewalled carbon nanotubes," Nano Letters, vol. 8, no. 2, pp. 463468, 2008.

[8] D. Takagi, H. Hibino, S. Suzuki, Y. Kobayashi, and Y. Homma, "Carbon nanotube growth from semiconductor nanoparticles," Nano Letters, vol. 7, no. 8, pp. 2272-2275, 2007.

[9] S. C. Lyu, B. C. Liu, C. J. Lee, H. K. Kang, C.-W. Yang, and C. Y. Park, "High-quality double-walled carbon nanotubes produced by catalytic decomposition of benzene," Chemistry of Materials, vol. 15, no. 20, pp. 3951-3954, 2003.

[10] M. Kumar and Y. Ando, "Chemical vapor deposition of carbon nanotubes: a review on growth mechanism and mass production," Journal of Nanoscience and Nanotechnology, vol. 10, no. 6, pp. 3739-3758, 2010.

[11] A. Moisala, A. G. Nasibulin, and E. I. Kauppinen, "The role of metal nanoparticles in the catalytic production of single-walled carbon nanotubes-a review," Journal of Physics: Condensed Matter, vol. 15, no. 42, pp. S3011-S3035, 2003.

[12] T. Moteki, Y. Murakami, S. Noda, S. Maruyama, and T. Okubo, "Zeolite surface as a catalyst support material for synthesis of single-walled carbon nanotubes," The Journal of Physical Chemistry C, vol. 115, no. 49, pp. 24231-24237, 2011.

[13] G. Allaedini, S. M. Tasirin, and J. Sahari, "Characterization of germanium nanoparticles via different methods of reaction temperature," International Journal of Engineering and Technical Research, vol. 2, no. 7, 2014.

[14] J. Sengupta, S. K. Panda, and C. Jacob, "Carbon nanotube synthesis from propane decomposition on a pre-treated ni overlayer," Bulletin of Materials Science, vol. 32, no. 2, pp. 135140, 2009.

[15] J. Sengupta and C. Jacob, "The effect of Fe and Ni catalysts on the growth of multiwalled carbon nanotubes using chemical vapor deposition," Journal of Nanoparticle Research, vol. 12, no. 2, pp. 457-465, 2010.

[16] S. S. Islam, K. A. Shah, H. S. Mavi, A. K. Shaukla, and S. Rath, "Raman study on single-walled carbon nanotubes with different laser excitation energies," Bulletin of Materials Science, vol. 30, no. 3, pp. 295-299, 2007.

[17] R. Saito, M. Hofmann, G. Dresselhaus, A. Jorio, and M. Dresselhaus, "Raman spectroscopy of graphene and carbon nanotubes," Advances in Physics, vol. 60, pp. 413-550, 2011. 

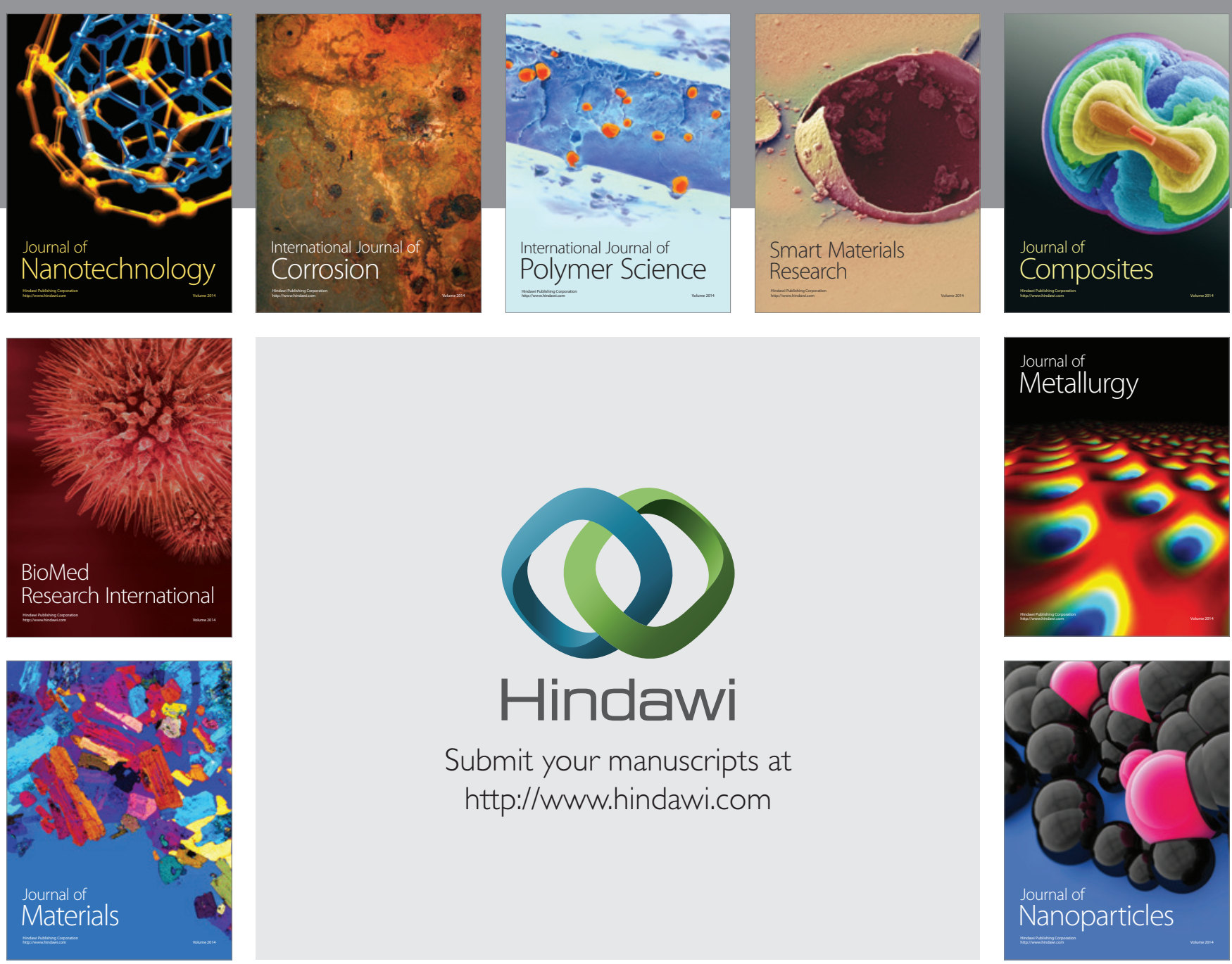

Submit your manuscripts at http://www.hindawi.com
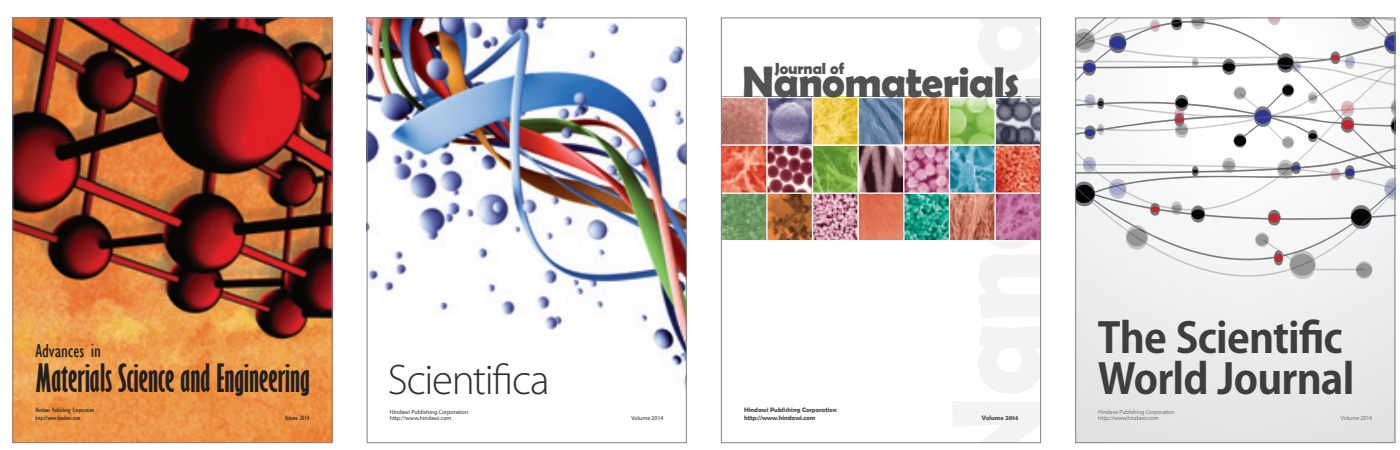

\section{The Scientific World Journal}
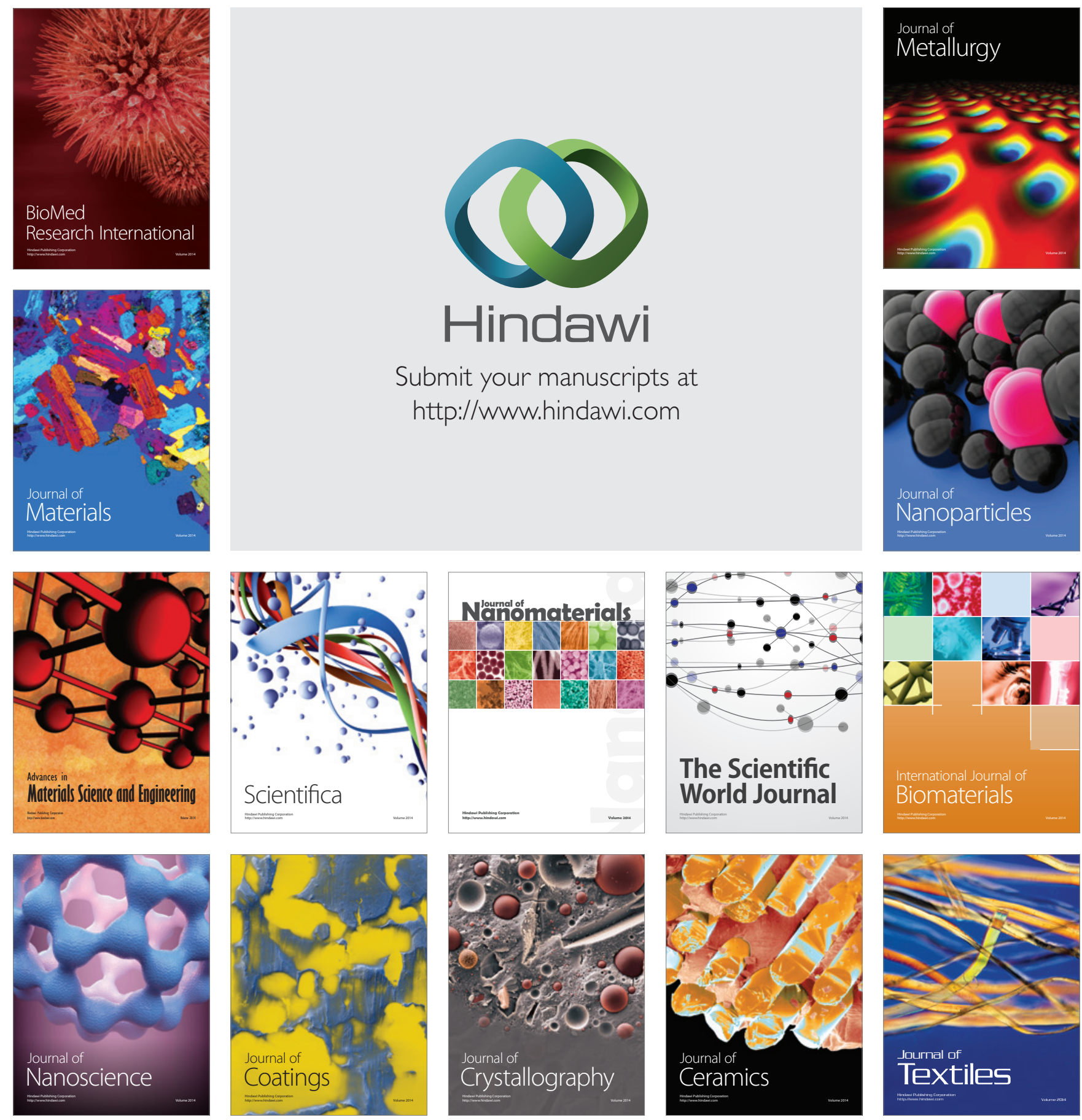